\title{
Prevalence of and Risk and Protective Factors for Depression in Female-to-Male Transgender Ontarians: Trans PULSE Project
}

\author{
Nooshin Khobzi Rotondi, Greta R. Bauer \\ The University of Western Ontario \\ Kyle Scanlon \\ 519 Church Street Community Centre \\ Matthias Kaay \\ Centre for Addiction and Mental Health \\ Robb Travers \\ Wilfrid Laurier University \\ Anna Travers \\ Rainbow Health Ontario
}

Nooshin Khobzi Rotondi, Department of Epidemiology \& Biostatistics, Schulich School of Medicine \& Dentistry, The University of Western Ontario; Greta R. Bauer, Department of Epidemiology \& Biostatistics, Schulich School of Medicine \& Dentistry, The University of Western Ontario; Kyle Scanlon, 519 Church Street Community Centre; Matthias Kaay, Rainbow Services, Centre for Addiction and Mental Health; Robb Travers, Department of Psychology, Wilfrid Laurier University; Anna Travers, Rainbow Health Ontario.

The authors acknowledge the support of grants from the Canadian Institutes of Health Research (Funding Reference \# 167492), and the Sexual and Gender Diversity: Vulnerability and Resilience (SVR) Research Team at UQAM (student research support for Nooshin Khobzi Rotondi). The Trans PULSE Project Steering Committee members are Greta Bauer, Robb Travers, Rebecca Hammond, Anjali K, Matthias Kaay, Jake Pyne, Nik Redman, Kyle Scanlon, and Anna Travers.

The authors thank Rupert Raj for providing valuable comments with regard to the mental health of trans people at the initial phases of this paper, Todd Coleman for translation of the abstract into French, and Michael Rotondi for his assistance in coding clustering variables. The authors also thank the Trans PULSE Community Engagement Team and the many trans people who shared their experiences for this study. Finally, N.K. Rotondi is currently affiliated with the Health Systems and Health Equity Research Group at the Centre for Addiction and Mental Health (Toronto, ON). Support to CAMH for salary of scientists and infrastructure has been provided by the Ontario Ministry of Health and Long-Term Care.

Correspondence regarding this article should be addressed to Nooshin Khobzi Rotondi, PhD, Health Systems and Health Equity Research Group, Centre for Addiction and Mental Health, 33 Russell St., Toronto, ON M5S 2S1. Telephone: 416-535-8501 (Ext. 4229). Email: Nooshin_Rotondi@camh.net 


\begin{abstract}
Although depression is understudied in transgender and transsexual communities, high prevalences have been reported. This paper presents original research from the Trans PULSE Project, an Ontario-wide, community-based initiative that surveyed 433 participants using respondent-driven sampling. The purpose of this analysis was to determine the prevalence of, and risk and protective factors for, depression among female-to-male (FTM) Ontarians ( $n=207)$. We estimate that $66.4 \%$ of FTMs have symptomatology consistent with depression. In multivariable analyses, sexual satisfaction was a strong protective factor. Conversely, experiencing transphobia and being at the stage of planning but not having begun a medical transition (hormones and/or surgery) adversely affected mental health in FTMs.
\end{abstract}

Keywords: transgender, female-to-male, depression, Ontario, risk and protective factors, respondent-driven sampling

\title{
INTRODUCTION
}

Studies internationally have shown a high prevalence of depression among trans (transgender, transsexual, or transitioned) people, with estimates ranging from $21 \%$ to $55 \%$ among those identifying on the female-to-male (FTM) spectrum (Clements-Nolle, Marx, Guzman, \& Katz, 2001; Couch et al., 2007; Hepp, Kraemer, Schnyder, Miller, \& Delsignore, 2005). The wide range of estimates is probably at least partially due to differences in measures of depression, which included lifetime prevalences based on DSM-IV criteria (27.3\%) (Hepp et al., 2005) and brief self-report scales that covered symptoms of clinical depression over a two-week period, resulting in prevalence estimates of 55\% (Clements-Nolle et al., 2001) and 21.3\% (Couch et al., 2007). The sampling methods also varied, including venue-based, clinical (Hepp et al., 2005), and Internet-based approaches (Couch et al., 2007). There are currently no estimates of depression among Canadian FTMs.

High estimates of depression among FTMs are not surprising given the marginalized status of trans people and the resulting stigmatization, harassment, and erasure they may experience (Lombardi, Wilchins, Priesing, \& Malouf, 2001, Bauer et al., 2009). Transphobia, a form of discrimination based on fear and hatred, may contribute to significant depression and poor mental health (Nemoto et al., 2006; Sugano et al., 2006), as well as reduced education and employment opportunities (Dean et al., 2000; Operario \& Nemoto, 2005).

Social isolation and a lack of overall social support are common among trans people (Gapka \& Raj, 2003; Maguen, Shipherd, \& Harris, 2005). Isolation is a determinant of emotional ill health and can exacerbate depression, anxiety, substance use, and suicidality (Gapka \& Raj, 2003). Although research on the effects of isolation on trans mental health is limited, social support is conceptualized as a crucial protective factor against the development of adverse mental health outcomes in other populations (Aro, 1994).

Where needed for treatment, hormones and sex-reassignment surgeries (SRS) can also affect psychological well-being. Female-to-males who have received testosterone reported higher quality of life scores than those who had not (Newfield, Hart, Dibble, \& Kohler, 2006). Depression ratings were also lower among post-operative FTMs vs. transsexuals who had not yet had surgery (Barret, 1998). While SRS may be an effective therapy for trans people (De Cuypere et al., 2006), the first year after SRS is typically not 
representative of the long-term emotional and psychological status of patients (De Cuypere et al., 2006). This suggests that many trans people require a period of adjustment following SRS.

Finally, studies of primarily non-trans populations have shown that depression often co-exists with chronic physical health problems, including chronic pain (Brown, 1990), osteoporosis (Coelho, Silva, Maia, Prata, \& Barros, 1999), HIV/AIDS (Rabkin, 2008), and cancer (Fann et al., 2008). While chronic physical conditions may greatly affect mood and depressive symptomatology, other mental health issues such as anxiety disorders also play a role. In fact, there is some evidence that anxiety and co-occurring depression are prevalent among trans people (Dean et al., 2000; Gapka \& Raj, 2003; Maguen et al., 2005). The relationship between chronic health issues and depressive symptomatology in trans people will be further examined in this study.

Much of the current research on the risk or protective factors for depression is based on the general (primarily non-trans) population, and although research in trans communities is sparse, some factors unique to trans people's experiences have been identified. Risk or protective factors that are strongly and consistently related to depression in the broader population (or in groups that also experience gender-related stigma, e.g., lesbian, gay, and bisexual communities) may also affect the mental health of trans people. This possibility is underresearched in the trans health literature, however, a limitation that is addressed in the present study using a large, network-based sample of trans people. The purpose of the current analysis was to estimate the prevalence of depression in FTM Ontarians and explore potential risk and protective factors among this group.

\section{METHODS}

\section{The Trans PULSE Project}

The Trans PULSE Project is a multi-phase community-based research initiative with the goal of improving the health of trans people through research driven by community needs. Trans PULSE is an Ontario-wide project, guided by a Steering Committee of ten investigators, seven of whom are trans. Phase I entailed a series of community soundings or focus groups that informed the development of a survey for Phase II. This paper draws upon data from Phase II.

\section{Sampling Design}

Recruitment was carried out between May 2009 and April 2010 using respondent-driven sampling (RDS), a systematic, network-based sampling method developed for the recruitment of hidden populations (Heckathorn, 1997). A group of 16 well-connected trans people served as "seeds" or initial participants. Seeds were recruited through community organizations, social venues, online, and by word-of-mouth, using a formal application process, and represented different community constituencies with respect to geographic location, income, age, ethnicity, and immigration status. Seeds were provided with three unique coupons to recruit eligible peers into the study. The coupons contained a randomly generated ticket number, information on the project's purpose, and information on how potential recruits could access the survey. Recruits received three coupons, as did their referred respondents. In RDS, this process is continued until the desired sample size is met or equilibrium is reached. Equilibrium is a state in which the estimates converge around a stable sample composition that does not change during subsequent cycles of recruitment (Heckathorn, 1997), and 
is usually obtained within four to five waves (Heckathorn, 2002). Twenty-two additional seeds were added once four to five waves of participants had been recruited. Limiting the number of recruits and providing incentives promote long recruitment chains (i.e., the chain-referral process consists of enough waves or cycles of recruitment), thereby ensuring that the final sample is not biased toward the characteristics of the seeds (Heckathorn, 1997). Primary incentives valued at $\$ 20$ were offered at the time of survey submission, with the participant choosing between receiving a gift card or donating their honorarium to a trans-related charity. Secondary incentives valued at $\$ 5$ for each of up to three participants recruited were offered for the final two months of recruitment.

Network referral patterns (i.e., who invited whom to participate) were tracked, and the personal network size of each participant was recorded. Network size data are used in weighted analyses to adjust for the over-sampling of respondents with larger social networks or groups that recruit greater numbers than other groups (Heckathorn, 2002).

The survey instrument was developed in English and available in multiple modes, including online, telephone interview with language interpretation (no respondent requested this option), and paper-andpencil. To be eligible, participants had to indicate they were trans; living, working, or receiving health care in Ontario; and aged 16 or over.

Of 433 FTM and MTF participants, 399 (92\%) completed the sections of the survey needed for this analysis. Of these, 207 were FTMs, although two were excluded for missing specific data on depression symptoms. Thus, the current analysis is based on this subpopulation of 205 FTMs, though data from the entire sample were used in calculating variances to account for the sampling design.

\section{Measures}

Outcome. Depression was assessed using the Center for Epidemiologic Studies Depression Scale (CES-D), a 20-item measure of past-week depressive symptom frequencies (Radloff, 1977). CES-D scores can range from 0 to 60 , with higher scores indicating the presence of more symptomatology. The outcome was dichotomized, with participants who scored $\geq 16$ defined as having symptomatology consistent with depression, in line with recommendations and general use (Boyd, Weissman, Thompson, \& Myers, 1982; Radloff, 1977). If more than four items were missing, the scale was not scored (Radloff, 1977). If one to four items were missing, the completed items were averaged and multiplied by 20 . A reliability analysis showed that the scale had strong internal consistency (Cronbach's alpha $[\alpha]=0.93$ ).

Potential risk and protective factors for depression. Because factors impacting depression in FTMs have not been well studied, potential risk and protective factors were considered if they (a) were associated with depression in general population studies; (b) were associated with depression in lesbian, gay, or bisexual communities, as these communities may experience gender-related discrimination; (c) had been suggested as potentially associated in trans research studies; or (d) were theorized as affecting depression based on the lived experiences of trans members of the research team.

Sociodemographics. Age was measured in years, and relationship status was categorized as single (dating or not dating) vs. in a relationship (monogamous, open, or polyamorous). Newcomer status was defined 
as living in Canada for $<5$ years, and area of residence was classified as Metropolitan Toronto vs. outside Toronto based on the first letter of the respondent's postal code.

Socioeconomic factors. Income-to-needs ratios were obtained by dividing the midpoint of the categories for household gross yearly income by the number of individuals supported on that income. Employment status was defined as unemployed (including those receiving disability, employment insurance, or general social assistance), other (including part-time employment, work leave, students, and retirees), and full-time employment. Additional socioeconomic variables tested for inclusion in multivariable models were education (completed high school or less, some postsecondary, postsecondary graduate) and housing (stably housed vs. not). The latter housing category included currently homeless individuals; those living in a group home, long-term care facility, motel or boarding house, squat, rehabilitation facility, or prison; and those couchsurfing or staying at a friend's house.

Transphobia, racism, and abuse. Childhood abuse history was assessed by asking respondents if they had ever experienced sexual or (separately) physical violence before age 16. Sexual violence was defined as unwanted, inappropriate, or hurtful sexual experience. Physical violence was defined to include pushing, grabbing, shoving, kicking, punching, or being "physically attacked in some other way." A composite variable was created: any sexual or physical abuse, no abuse, and "rather not answer" or "don't know." An 11-item scale for transphobia was constructed to measure the frequency of direct and indirect transphobic experiences, including discrimination and harassment, exposure to ideas of non-normalcy, familial embarrassment, or being fetishized. Possible scores ranged from 0 to 33, and higher scores indicated greater transphobia. This scale was modified significantly from a homophobia scale used by Diaz, Ayala, Bein, Henne, \& Marin (2001) to reflect differences in the ways that homophobia and transphobia are typically experienced. For example, gay or bisexual people may have heard negative things about gay people when they were children, whereas most trans people have heard nothing about trans people as children. A 10-item scale (scores ranging from 0 to 30) was used to assess childhood and adult experiences of racism, including verbal harassment, physical violence, and discrimination. This measure was adapted from a racism scale used by Diaz et al. (2001) for gay and bisexual men, since that scale included items on race-based sexual objectification and difficulty in finding lovers that likely apply well to trans people. The measure was dichotomized (no experiences of racism vs. any experience of racism) based on the distribution in our data. The transphobia and racism scales showed high levels of internal consistency: transphobia, Cronbach's $\alpha=0.81$; racism, $\alpha=0.92$.

Social and identity support. Availability of functional social support was assessed using the 19-item Medical Outcomes Study Social Support Survey scale (Sherbourne \& Stewart, 1991), which captures tangible, emotional/informational, and affectionate dimensions of support, as well as positive social interactions. Scores ranged from 1 to 5 with higher values indicating greater support $(\alpha=0.97)$. Identity support, defined as perceived or expected support for one's gender identity or expression from different sources (e.g., parent[s], child[ren], trans friends, co-workers) was measured using a metric developed for our study. Options for 16 possible sources of identity support were scored from 1 (not at all supportive) to 4 (very supportive). Scores were averaged across completed items for actual or expected experiences of identity support. Finally, participation in voluntary organizations in the past year was categorized as moderate to high involvement (at least once a month) vs. little or no involvement. 
Hormone therapy and sex-reassignment surgeries (SRS). Respondents were asked whether they currently take hormones. Stage of medical transition was assessed by asking participants which situation best applied to them: have medically transitioned (hormones and/or surgery), in the process of medically transitioning, planning to medically transition, not planning to medically transition, the concept of "transitioning" does not apply, and not sure whether or not to medically transition. "Not planning to medically transition" and "the concept of 'transitioning' does not apply" were grouped into one category. Respondents were also asked if they had undergone any of a number of sex reassignment procedures (e.g., orchiectomy, vaginoplasty, phalloplasty, mastectomy), and the year in which they had undergone each surgery. Participants were classified as having had recent surgery (between 2008 and 2010), non-recent surgery (before 2008), and no sex reassignment surgery. Those who indicated undergoing multiple procedures both recently and before 2008 were coded as having had recent surgery.

Living in felt gender (coming out). Respondents indicated whether they were currently living in their felt gender (full-time, part-time, no), and if yes, at what age they had begun doing so. A composite variable was constructed: living full-time in felt gender for $\leq 3$ years, living full-time in felt gender for $>3$ years, and living in felt-gender part-time or not at all.

Gender-related passing, whether one is accepted or regarded as a member of the gender with which one identifies, was also assessed in our study, given that not passing may result in targeting for humiliation, discrimination, and violence. Participants indicated the frequency with which they encountered people who knew they were trans without being told so. This question was recoded into three categories: rarely pass, sometimes or often pass, and almost always or always pass.

Chronic health issues and sexual satisfaction. Respondents who were not usually pain-free or physically comfortable, and/or reported that they had been diagnosed with HIV, cancer, fibromyalgia, osteoporosis, or diabetes were defined as experiencing major chronic physical health issues. These particular conditions were strongly and consistently related to depression in the literature. Those who reported being diagnosed with schizophrenia, borderline personality disorder, dissociative identity disorder, and/or anxiety disorders were coded as experiencing major mental health issues. Finally, sexual satisfaction was measured using a 5-item subscale ( $\alpha=0.96)$ from the Multidimensional Sexual Self-Concept Questionnaire (Snell, 1998).

\section{Statistical Analyses}

Missing data. Income-to-needs ratio had the greatest proportion of missing values (14\%), which is likely non-ignorable given the sensitive nature of the variable. Due to the statistical relationship between income and other income-related variables (Pigott, 2001), we used less sensitive, surrogate variables (education and employment status) in multivariable modelling. Newcomer status was missing for $8 \%$ of participants and was excluded because of a lack of (a) variability, and (b) association with the outcome in complete case analysis. Upon exclusion of the preceding variables from multivariable analysis, 309 FTM and male-to-female respondents had complete data prior to imputation. Of the 90 participants with any missing data, $89 \%$ were only missing values for one or two variables. In addition, $90 \%$ of variables included in this analysis were missing data on $3 \%$ or fewer respondents. Since missing data were minimal, a straightforward imputation technique (overall mean and median), was employed in order to preserve the sample size by reducing the 
loss of cases resulting from list-wise deletion in multiple regression. Imputation was not employed for the outcome, descriptive statistics, and bivariate analyses. Following imputation, 391 participants had complete data for multivariable analyses, including 205 FTMs ( 8 of 399 respondents had missing values for the outcome and were thus excluded). Note that single imputation may reduce variability in scores, resulting in the underestimation of variances and standard errors.

Given that our entire sample included both MTFs and FTMs, missing data were addressed for the full data set. This was necessary because while our paper was limited to FTMs, full-sample data were used in multivariable regression to ensure correct analyses of the subpopulation (Berglund, 2009). This latter point is further elaborated below (see Bivariate and Multivariable Regression).

\section{Prevalence Estimation}

Weighted prevalence estimates for Ontario FTMs and associated 95\% confidence intervals were calculated for all variables of interest using RDSAT version 6.0 (Volz, Wejnert, Degani, \& Heckathorn, 2007). Estimates were weighted using information on proportional recruitments across groups and mean network sizes for each group (Heckathorn, 1997). This permitted calculation of population estimates that (a) compensate for oversampling of groups with larger network sizes, and (b) control for differences in recruitment effectiveness and degrees of homophily, i.e., preference for connections to one's own group.

\section{Bivariate and Multivariable Regression}

Individualized weights for the depression outcome variable were computed. When these weights are generated for the dependent variable, they can weight the entire data set for regression analyses (RDSAT 5.6 User Manual, 2006). Comparisons between weighted and unweighted data showed considerable differences; weighted results are thus presented in this paper.

Adjustments for the lack of independence among respondents were applied to regression models using strata and cluster statements in SAS SURVEYLOGISTIC procedures. Respondents recruited from 0 to 3 eligible peers, thus individual-level errors were potentially correlated with the explanatory variables in the model. In this study, participants who shared a recruiter were treated as a cluster. Furthermore, respondents who shared a seed were members of the same recruitment tree, the latter representing a higher level of clustering in which shared recruiter clusters were nested. Finally, analyses specific to FTMs were carried out using the entire sample. This is necessary with correlated or clustered survey data analyzed using SAS SURVEYLOGISTIC procedures, because merely subsetting the data to the subpopulation of interest may result in under-estimated variances (Berglund, 2009). The domain statement in SURVEYLOGISTIC was used to produce statistically correct standard errors for analyses of subpopulations (Berglund, 2009). While there are no standardized methods for regression using RDS data, our approach accounts for the networked data structure, and represents a development over commonly used methods that present weighted or unweighted models with no variance adjustments for clustering.

SAS version 9.2 (SAS Institute, 2010) was used for all logistic regression analyses. Bivariate analyses were conducted to compute odds ratios and corresponding $95 \%$ confidence intervals, accounting for weighting and clustering. Interval variables were treated as continuous, and a series of dummy variables 
were created for categorical variables. For the multivariable analysis, multiple logistic regression models were built as follows:

(1) A weighted backward elimination procedure was used to reduce the number of general population risk or protective factors in the final model. Age, a key sociodemographic variable, was forced to remain in the model. A criterion of $p>.15$ was used to select variables for removal.

(2) Variables retained through the backward elimination procedure were included, along with all transrelated variables, in weighted multiple logistic regression models that adjusted for clustering.

(3) Conceptually similar and strongly associated transition-related variables (stage of medical transition, surgery, current hormone use, and whether living in felt gender) were tested to determine if any should be removed, by comparing different models using the Akaike information criterion (AIC).

\section{RESULTS}

\section{Characteristics of FTM Ontarians}

Estimated population frequencies of characteristics of Ontario FTMs are described in Table 1. In general, 20-29 year olds represented the largest age group among FTMs in Ontario; the mean age was 29.7 (standard deviation $[\mathrm{SD}]=9.6$ ) years. While the majority of FTMs had at least some college or university education, $16.6 \%, 95 \%$ CI $[9.9,23.9]$ were unemployed, and 50.0\% [38.2, 60.5] fell in the lowest income-to-needs ratio category $(<\$ 15,000 /$ person). Nearly half of FTM Ontarians were at least moderately involved in community organizations and lived in Metropolitan Toronto. Most FTMs were also stably housed and in a relationship; few were newcomers to Canada. Childhood abuse was experienced by an estimated $65.7 \%$ [57.3, 75.1] of FTMs in Ontario. In addition, 63.0\% [53.5, 72.2] reported to have been diagnosed with schizophrenia, borderline personality disorder, dissociative identity disorder, or anxiety disorders.

With regard to factors unique to the trans community, an estimated $50.8 \%, 95 \%$ CI $[41.4,59.8]$ of FTM Ontarians almost always or always passed in their felt gender. The majority of FTMs had experienced moderate to high levels of transphobia. Most had either medically transitioned, or were planning to but had not begun, and $31.8 \%[22.5,41.4]$ had been living full-time in their felt gender for $>3$ years.

\section{Risk and Protective Factors Associated with Depression}

An estimated $66.4 \%, 95 \%$ CI $[59.2,75.2]$ of Ontario FTMs scored at least 16 on the CES-D (sample frequency, $n=116$ ), and were thus classified as having symptomatology consistent with depression. The scores ranged from 0 (no depressive symptomatology) to 57, with a mean of $20.3(S D=13.0$ ), and a median of 19.0.

Bivariate analyses are presented in Table 2. Wald chi-square tests of association revealed that the odds of depressive symptomatology among FTMs who had been diagnosed with a major mental health disorder were almost three times that of those who had never been diagnosed with any of the indicator conditions. In addition, higher levels of social support and sexual satisfaction were associated with reduced odds of depression. Of the trans-specific factors, more frequent exposure to transphobia was significantly associated with higher odds of depressive symptomatology, with each one-point increase on the transphobia scale associated with a $12 \%$ increase in the odds of depression. Conversely, those experiencing higher levels of identity 
Table 1

Weighted Prevalence Estimates of General Population and Trans-specific Risk Factors for Depression among Female-to-Male Ontarians

\begin{tabular}{|c|c|c|c|}
\hline Characteristic & $N$ & $\%{ }^{a}$ & $95 \% \mathrm{CI}^{\mathrm{a}}$ \\
\hline \multicolumn{4}{|l|}{ General population risk factors } \\
\hline \multicolumn{4}{|l|}{ Age, y (range 16-64) } \\
\hline $16-19$ & 20 & 11.7 & {$[5.3,20.4]$} \\
\hline $20-29$ & 100 & 48.1 & {$[37.7,57.3]$} \\
\hline $30-39$ & 53 & 24.8 & {$[16.9,33.5]$} \\
\hline $40-49$ & 25 & 11.8 & {$[5.3,20.3]$} \\
\hline$\geq 50$ & 9 & 3.6 & {$[0.3,7.7]$} \\
\hline \multicolumn{4}{|l|}{ Area of residence } \\
\hline Metropolitan Toronto & 120 & 42.8 & {$[28.8,53.6]$} \\
\hline Outside Metropolitan Toronto & 79 & 57.2 & {$[46.4,71.2]$} \\
\hline \multicolumn{4}{|l|}{ Income-to-needs ratio, $\$ /$ person } \\
\hline$<15,000$ & 79 & 50.0 & {$[38.2,60.5]$} \\
\hline 15,000 to $<30,000$ & 60 & 34.6 & {$[25.1,46.2]$} \\
\hline 30,000 to $<45,000$ & 19 & 4.8 & {$[1.9,7.6]$} \\
\hline$\geq 45,000$ & 23 & 10.6 & {$[4.7,18.0]$} \\
\hline \multicolumn{4}{|l|}{ Education } \\
\hline High school or less & 50 & 35.5 & {$[27.2,45.4]$} \\
\hline Some college or university & 50 & 25.7 & {$[17.8,33.4]$} \\
\hline Postsecondary graduate & 106 & 38.7 & {$[29.2,47.7]$} \\
\hline \multicolumn{4}{|l|}{ Employment status } \\
\hline Full time & 83 & 39.3 & {$[30.3,47.0]$} \\
\hline Unemployed & 29 & 16.6 & {$[9.9,23.9]$} \\
\hline Other ${ }^{\mathrm{b}}$ & 94 & 44.1 & {$[35.8,54.1]$} \\
\hline \multicolumn{4}{|l|}{ Housing } \\
\hline Stable & 190 & 95.5 & {$[92.0,98.5]$} \\
\hline Unstable & 16 & 4.5 & {$[1.5,8.0]$} \\
\hline \multicolumn{4}{|l|}{ Relationship status } \\
\hline Single & 88 & 48.2 & {$[39.0,57.4]$} \\
\hline In relationship & 118 & 51.8 & {$[42.6,61.1]$} \\
\hline \multicolumn{4}{|l|}{ Newcomer status } \\
\hline$<5$ yrs in Canada & 5 & 2.0 & {$[0.4,4.5]$} \\
\hline$\geq 5 \mathrm{yrs}$ in Canada & 186 & 98.0 & {$[95.5,99.6]$} \\
\hline \multicolumn{4}{|l|}{ Childhood abuse } \\
\hline Any abuse ${ }^{c}$ & 145 & 65.7 & {$[57.3,75.1]$} \\
\hline No abuse & 48 & 28.4 & {$[20.1,36.1]$} \\
\hline Don't know/rather not answer & 14 & 5.9 & {$[1.9,10.4]$} \\
\hline
\end{tabular}


Table 1

(Continued)

\begin{tabular}{|c|c|c|c|}
\hline Characteristic & $N$ & $\%^{\mathrm{a}}$ & $95 \% \mathrm{CI}^{\mathrm{a}}$ \\
\hline \multicolumn{4}{|l|}{ Community involvement } \\
\hline Moderate to high involvement & 116 & 49.9 & {$[41.1,59.9]$} \\
\hline Little or no involvement & 90 & 50.1 & {$[40.1,58.9]$} \\
\hline \multicolumn{4}{|l|}{ Major mental health issues } \\
\hline Yes $^{\mathrm{d}}$ & 108 & 63.0 & {$[53.5,72.2]$} \\
\hline No & 94 & 37.0 & {$[27.9,46.5]$} \\
\hline \multicolumn{4}{|l|}{ Chronic physical health issues } \\
\hline Yes & 79 & 38.7 & {$[29.4,46.8]$} \\
\hline No & 128 & 61.3 & {$[53.3,70.7]$} \\
\hline \multicolumn{4}{|l|}{ Racism } \\
\hline Any exposure & 102 & 50.0 & {$[40.2,59.0]$} \\
\hline No exposure & 102 & 50.0 & {$[41.0,59.8]$} \\
\hline \multicolumn{4}{|l|}{ Social support ${ }^{\mathrm{e}}$} \\
\hline 1.0 to $<2.5$ & 29 & 16.4 & {$[8.9,24.4]$} \\
\hline 2.5 to $<3.5$ & 42 & 21.7 & {$[14.6,29.9]$} \\
\hline 3.5 to 5.0 & 135 & 61.9 & {$[52.3,71.4]$} \\
\hline \multicolumn{4}{|l|}{ Sexual satisfaction ${ }^{\mathrm{e}}$} \\
\hline$<1.0$ & 50 & 30.0 & {$[21.9,40.2]$} \\
\hline 1.0 to $<2.5$ & 69 & 35.1 & {$[26.5,43.5]$} \\
\hline 2.5 to 4.0 & 73 & 34.9 & {$[25.5,43.8]$} \\
\hline \multicolumn{4}{|l|}{ Trans-specific risk factors } \\
\hline \multicolumn{4}{|l|}{ Passing } \\
\hline Rarely or never & 47 & 21.4 & {$[14.8,28.4]$} \\
\hline Half the time/often & 67 & 27.8 & {$[20.8,36.0]$} \\
\hline (Almost) always & 90 & 50.8 & {$[41.4,59.8]$} \\
\hline \multicolumn{4}{|l|}{ Transphobia $^{\mathrm{e}}$} \\
\hline$<11.0$ & 64 & 39.6 & {$[30.7,49.5]$} \\
\hline 11.0 to $<21.0$ & 114 & 48.3 & {$[38.3,57.4]$} \\
\hline 21.0 to 31.0 & 27 & 12.1 & {$[6.3,19.0]$} \\
\hline \multicolumn{4}{|l|}{ Living in felt gender } \\
\hline Full-time $\leq 3 \mathrm{yrs}$ & 57 & 17.9 & {$[12.2,24.7]$} \\
\hline Full-time $>3 \mathrm{yrs}$ & 87 & 31.8 & {$[22.5,41.4]$} \\
\hline Part-time or not at all & 60 & 50.3 & {$[39.7,60.5]$} \\
\hline
\end{tabular}


Table 1

(Continued)

\begin{tabular}{|c|c|c|c|}
\hline Characteristic & $N$ & $\%^{\mathrm{a}}$ & $95 \% \mathrm{CI}^{\mathrm{a}}$ \\
\hline \multicolumn{4}{|l|}{ Identity support $^{\mathrm{e}}$} \\
\hline 1.0 to $<2.0$ & 6 & 4.6 & {$[0.3,7.6]$} \\
\hline 2.0 to $<3.0$ & 44 & 30.8 & {$[22.4,41.3]$} \\
\hline 3.0 to 4.0 & 153 & 64.5 & {$[55.7,74.3]$} \\
\hline \multicolumn{4}{|l|}{ Current hormone use } \\
\hline Yes & 117 & 38.5 & {$[28.7,46.2]$} \\
\hline No & 89 & 61.5 & {$[53.8,71.3]$} \\
\hline \multicolumn{4}{|l|}{ Stage of medical transition } \\
\hline Medically transitioned & 78 & 21.9 & {$[13.6,28.3]$} \\
\hline In the process & 48 & 16.9 & {$[10.6,20.5]$} \\
\hline Planning, but not begun & 43 & 40.1 & {$[30.7,48.9]$} \\
\hline Not planning/concept does not apply & 14 & 10.4 & {$[5.9,24.0]$} \\
\hline Not sure & 24 & 10.7 & {$[5.8,14.9]$} \\
\hline \multicolumn{4}{|l|}{ Surgery } \\
\hline Recent surgery & 31 & 10.6 & {$[5.7,15.2]$} \\
\hline Surgery before 2008 & 53 & 14.0 & {$[9.0,20.9]$} \\
\hline Never had surgery & 115 & 75.4 & {$[66.9,82.9]$} \\
\hline
\end{tabular}

Note: CI, confidence interval; $n$, sample frequency; y, years.

${ }^{a}$ Weighted prevalence estimates and 95\% CIs obtained from RDSAT version 6.0.

${ }^{\mathrm{b}}$ Other employment includes part-time, on leave from work, students, and retired participants.

${ }^{\mathrm{c}}$ Any childhood abuse includes experiences of sexual and/or physical abuse before age 16 .

d 87 were diagnosed only with anxiety disorders; 21 had been diagnosed with schizophrenia, borderline personality disorder, and/or dissociative identity disorder, with or without anxiety disorders.

${ }^{\mathrm{e}}$ Continuous/scale measures: higher scores indicate greater levels of social support, sexual satisfaction, transphobia, and identity support.

support were significantly less likely to exhibit symptoms consistent with depression. The odds of depression were 2.8 times greater for FTMs not currently using hormones compared with current users. Finally, FTM Ontarians who had never had surgery were significantly more likely to score $\geq 16$ on the CES-D than FTMs who had undergone any surgical procedure before 2008. Those who were planning to medically transition (hormones and/or surgery) but had not begun were five times more likely to be depressed than FTMs who had medically transitioned.

Table 3 displays the results from the multivariable analysis. Of the general population risk and protective factors tested for removal in backward elimination, employment status, housing, relationship status, community involvement, having a major chronic physical health condition, exposure to racism, and area 
Table 2

Bivariate Associations between Depression and Risk Factors of Interest

\begin{tabular}{|c|c|c|}
\hline Risk factors & $\mathrm{OR}^{\mathrm{a}}$ & $95 \% \mathrm{CI}^{\mathrm{a}}$ \\
\hline General population & & \\
\hline Age (y) & 1.02 & {$[0.98,1.06]$} \\
\hline $\begin{array}{l}\text { Area of residence } \\
\text { Outside Metropolitan Toronto } \\
\text { Metropolitan Toronto }\end{array}$ & $\begin{array}{l}1.37 \\
1.00\end{array}$ & $\begin{array}{l}{[0.60,3.15]} \\
\text { Referent }\end{array}$ \\
\hline $\begin{array}{l}\text { Income-to-needs ratio, } \$ \text { person } \\
\quad<15,000 \\
15,000 \text { to }<30,000 \\
30,000 \text { to }<45,000 \\
\geq 45,000\end{array}$ & $\begin{array}{l}3.02 \\
1.57 \\
1.78 \\
1.00\end{array}$ & $\begin{array}{l}{[0.69,13.22]} \\
{[0.35,7.09]} \\
{[0.28,11.18]} \\
\text { Referent }\end{array}$ \\
\hline $\begin{array}{l}\text { Education } \\
\text { High school or less } \\
\text { Some college or university } \\
\text { Postsecondary graduate }\end{array}$ & $\begin{array}{l}2.30 \\
0.82 \\
1.00\end{array}$ & $\begin{array}{l}{[0.80,6.66]} \\
{[0.30,2.30]} \\
\text { Referent }\end{array}$ \\
\hline $\begin{array}{l}\text { Employment status } \\
\text { Unemployed } \\
\text { Other }^{\mathrm{b}} \\
\text { Full time }\end{array}$ & $\begin{array}{l}2.27 \\
0.84 \\
1.00\end{array}$ & $\begin{array}{l}{[0.61,8.37]} \\
{[0.35,2.01]} \\
\text { Referent }\end{array}$ \\
\hline $\begin{array}{l}\text { Housing } \\
\text { Unstable } \\
\text { Stable }\end{array}$ & $\begin{array}{l}0.79 \\
1.00\end{array}$ & $\begin{array}{l}{[0.19,3.19]} \\
\text { Referent }\end{array}$ \\
\hline $\begin{array}{l}\text { Relationship status } \\
\text { Single } \\
\text { In relationship }\end{array}$ & $\begin{array}{l}1.35 \\
1.00\end{array}$ & $\begin{array}{l}{[0.61,2.98]} \\
\text { Referent }\end{array}$ \\
\hline $\begin{array}{l}\text { Newcomer status } \\
\geq 5 \text { yrs in Canada } \\
<5 \text { yrs in Canada }\end{array}$ & $\begin{array}{l}1.18 \\
1.00\end{array}$ & $\begin{array}{l}{[0.14,9.84]} \\
\text { Referent }\end{array}$ \\
\hline $\begin{array}{l}\text { Childhood abuse } \\
\text { Any abuse } \\
\text { Don't know/rather not answer } \\
\text { No abuse }\end{array}$ & $\begin{array}{l}2.16 \\
0.61 \\
1.00\end{array}$ & $\begin{array}{l}{[0.81,5.72]} \\
{[0.08,4.81]} \\
\text { Referent }\end{array}$ \\
\hline $\begin{array}{l}\text { Community involvement } \\
\text { Little or no involvement } \\
\text { Moderate to high involvement }\end{array}$ & $\begin{array}{l}0.65 \\
1.00\end{array}$ & $\begin{array}{l}{[0.30,1.44]} \\
\text { Referent }\end{array}$ \\
\hline $\begin{array}{l}\text { Major mental health issues } \\
\text { Yes } \\
\text { No }\end{array}$ & $\begin{array}{l}2.64 \\
1.00\end{array}$ & $\begin{array}{l}{[1.10,6.36]^{*}} \\
\text { Referent }\end{array}$ \\
\hline
\end{tabular}


Table 2

(Continued)

\begin{tabular}{|c|c|c|}
\hline Risk factors & $\mathrm{OR}^{\mathrm{a}}$ & $95 \% \mathrm{CI}^{\mathrm{a}}$ \\
\hline \multicolumn{3}{|l|}{ Chronic physical health issues } \\
\hline Yes & 2.47 & {$[0.97,6.30]$} \\
\hline No & 1.00 & Referent \\
\hline \multicolumn{3}{|l|}{ Racism } \\
\hline Any exposure & 1.31 & {$[0.59,2.92]$} \\
\hline No exposure & 1.00 & Referent \\
\hline Social support & 0.56 & {$[0.33,0.94]^{*}$} \\
\hline Sexual satisfaction & 0.55 & {$[0.40,0.75]^{*}$} \\
\hline \multicolumn{3}{|l|}{ Trans-specific } \\
\hline \multicolumn{3}{|l|}{ Passing } \\
\hline Rarely or never & 0.76 & {$[0.28,2.07]$} \\
\hline Half the time/often & 0.94 & {$[0.36,2.44]$} \\
\hline (Almost) always & 1.00 & Referent \\
\hline Transphobia & 1.12 & {$[1.05,1.21]^{*}$} \\
\hline \multicolumn{3}{|l|}{ Living in felt gender } \\
\hline Part-time or not at all & 2.08 & {$[0.74,5.88]$} \\
\hline Full-time $\leq 3$ yrs & 0.69 & {$[0.23,2.05]$} \\
\hline Full-time $>3$ yrs & 1.00 & Referent \\
\hline Identity support & 0.33 & {$[0.13,0.82]^{*}$} \\
\hline \multicolumn{3}{|l|}{ Current hormone use } \\
\hline No & 2.80 & {$[1.29,6.08]^{*}$} \\
\hline Yes & 1.00 & Referent \\
\hline \multicolumn{3}{|l|}{ Surgery } \\
\hline Recent surgery & 1.84 & {$[0.49,6.87]$} \\
\hline Never had surgery & 5.29 & {$[1.88,14.85]^{*}$} \\
\hline Surgery before 2008 & 1.00 & Referent \\
\hline \multicolumn{3}{|l|}{ Stage of medical transition } \\
\hline Not planning/concept does not apply & 1.45 & {$[0.23,9.34]$} \\
\hline Not sure & 1.26 & {$[0.33,4.84]$} \\
\hline Planning, but not begun & 5.15 & {$[1.64,16.16]^{*}$} \\
\hline In the process & 1.23 & {$[0.46,3.29]$} \\
\hline Medically transitioned & 1.00 & Referent \\
\hline
\end{tabular}

Note: OR, odds ratio; $\mathrm{CI}$, confidence interval; y, years.

${ }^{a}$ Standard errors and odds ratios were adjusted for sampling design (individualized weights; recruitment tree, and shared recruiter clusters) using surveylogistic procedures in SAS version 9.2.

${ }^{\mathrm{b}}$ Other employment includes part-time, on leave from work, students, and retired participants.

${ }^{\mathrm{c}}$ Any childhood abuse includes experiences of sexual and/or physical abuse before age 16.

$* p<0.05$ 
of residence were dropped from the final model. Furthermore, the following trans-specific variables were removed from the final model: current hormone use and surgery. The smallest AIC value was obtained upon removal of these variables, resulting in a more precise and better specified model.

Three factors remained significantly associated with depression in the final weighted logistic regression model, controlling for other variables in the model and adjusted for recruitment tree and shared recruiter clusters. The odds of having symptoms consistent with depression were increased as experiences of transphobia increased, and among those who were planning to transition but had not begun. Conversely, the odds of depressive symptomatology decreased as sexual satisfaction increased. More specifically, FTMs who were planning to medically transition but had not begun had 6.33 times higher odds of depression than those who had transitioned. Each one-point increase in transphobic experiences was associated with a $17 \%$ increase in the odds of depressive symptomatology, and each one-point increase in sexual satisfaction was associated with a $50 \%$ reduction.

\section{DISCUSSION}

While this study is the first to examine risk and protective factors for depression among FTMs, findings must be interpreted cautiously. Our research is both exploratory (hypothesis-generating) and analytical in nature, and given the cross-sectional study design, we cannot make causal inferences. Moreover, we did not have a comparison group of non-trans Ontarians; thus, risk and protective factors identified are those that contribute to differences in the odds of depressive symptomatology between FTMs. These may not be the same factors that contribute to inequity between trans and non-trans populations with regard to mental health.

In general, we found that FTM Ontarians were predominantly young adults, highly educated, in a relationship, and living outside Toronto. The demographic characteristics were similar to trans people in the United States (Rosser, Oakes, Bockting, \& Miner, 2007). About two thirds of FTMs scored at least 16 on the CES-D, and were thus identified as currently having symptoms consistent with depression. This prevalence is consistent with estimates from convenience studies of FTMs in other locations (Clements-Nolle et al., 2001; Couch et al., 2007; Hepp et al., 2005), and is probably substantially higher than estimates for Ontario's population overall. According to the Canadian Community Health Survey (CCHS), 4.8\%, 95\% CI $[4.3,5.3]$ of Ontarians were identified as being depressed in the past 12 months (Lesage et al., 2006). This comparison is limited because trans Ontarians are generally younger than the non-trans Ontario population, and because the measurement tool and time frame used in the CCHS differ from the CES-D. Despite these differences, however, it is reasonable to conclude that the burden of depression is probably greater among FTM Ontarians than in the general Ontario population. The longer the time frame used to inquire about symptoms, the higher the rate of depression (Rabkin, 2008). Thus, estimates from the CCHS would probably be even lower if a shorter time frame were used to assess depressive symptomatology.

Bivariate analyses revealed that several general population and trans-specific risk or protective factors were significantly associated with depression; for example, we observed statistically significant protective effects of social support and identity support on depressive symptomatology. However, both support-related variables became non-significant in the final multiple logistic regression model. Given that few other studies have investigated the potential factors associated with depression among trans people, it is difficult to 
Table 3

Multiple Logistic Regression Model for Depression Regressed onto General Population and Trans-specific Risk Factors

\begin{tabular}{|c|c|c|}
\hline Risk factors & $\mathrm{OR}^{\mathrm{a}}$ & $95 \% \mathrm{CI}^{\mathrm{a}}$ \\
\hline Age (y) & 1.01 & {$[0.96,1.07]$} \\
\hline \multicolumn{3}{|l|}{ Education } \\
\hline High school or less & 2.17 & {$[0.25,18.56]$} \\
\hline Some college or university & 1.23 & {$[0.33,4.56]$} \\
\hline Postsecondary graduate & 1.00 & Referent \\
\hline \multicolumn{3}{|l|}{ Childhood abuse } \\
\hline Any abuse & 2.96 & {$[0.94,9.30]$} \\
\hline Don't know/rather not answer & 0.66 & {$[0.06,6.84]$} \\
\hline No abuse & 1.00 & Referent \\
\hline \multicolumn{3}{|l|}{ Major mental health issues } \\
\hline Yes & 2.56 & {$[0.91,7.19]$} \\
\hline No & 1.00 & Referent \\
\hline Social support & 0.80 & {$[0.46,1.39]$} \\
\hline Sexual satisfaction & 0.50 & {$[0.32,0.76]^{* *}$} \\
\hline \multicolumn{3}{|l|}{ Passing } \\
\hline Rarely or never & 2.13 & {$[0.62,7.33]$} \\
\hline Half the time/often & 2.42 & {$[0.71,8.20]$} \\
\hline (Almost) always & 1.00 & Referent \\
\hline Transphobia & 1.17 & {$[1.06,1.29]^{* *}$} \\
\hline Identity support & 0.60 & {$[0.18,1.95]$} \\
\hline \multicolumn{3}{|l|}{ Living in felt gender } \\
\hline Part-time or not at all & 2.04 & {$[0.61,6.78]$} \\
\hline Full-time $\leq 3$ yrs & 0.46 & {$[0.11,1.97]$} \\
\hline Full-time $>3$ yrs & 1.00 & Referent \\
\hline \multicolumn{3}{|l|}{ Stage of medical transition } \\
\hline Not planning/concept does not apply & 0.60 & {$[0.06,6.68]$} \\
\hline Not sure & 0.53 & {$[0.07,4.10]$} \\
\hline Planning, but not begun & 6.33 & {$[1.40,28.66]^{*}$} \\
\hline In the process & 0.53 & {$[0.09,3.02]$} \\
\hline Medically transitioned & 1.00 & Referent \\
\hline
\end{tabular}

Note: OR, odds ratio; $\mathrm{CI}$, confidence interval; y, years.

${ }^{a}$ Standard errors and odds ratios were adjusted for sampling design (individualized weights; recruitment tree, and shared recruiter clusters) using SURVEYLOGISTIC procedures in SAS version 9.2.

$* p<0.05 ; * * p<0.01$ 
determine why particular characteristics failed to remain statistically significant. An explanation for the present finding may relate to the protective role played by sexual satisfaction in multivariable analyses. Our study indicates that FTMs who were highly satisfied with the sexual aspects of their lives were significantly less likely to exhibit symptoms consistent with depression (versus those experiencing lower levels of satisfaction). Given that many trans people face difficulty in finding sexual partners or dealing with disclosure of non-concordant genders and bodies, it follows that having an accepting and supportive partner may result in increased levels of sexual satisfaction. It is therefore possible that sexual satisfaction not only impacts the mental health of FTMs through direct beneficial effects, but it may also mediate the effects of social and identity support. In fact, additional tests revealed that identity support was significantly associated with sexual satisfaction; however, the plausibility of the mediating relationship may depend on the source of support, particularly support received from sexual partners. Depressive disorders may also lead to a loss of sexual interest, characterized by loss of libido or decrease of sexual desire (Baldwin, 2001). Thus, due to the cross-sectional nature of the present study, the reverse relationship is also possible; that is, depressed FTMs may be more likely to experience lower levels of sexual satisfaction.

Transphobia remained significant in multivariable analyses, indicating furthermore that FTMs exposed to greater levels of discrimination were more likely to have symptoms of depression than those with less frequent experiences of transphobia, whether comparing across all trans people, or among those who were similar on factors included in our multiple regression model. This result is not unexpected given that discrimination, stigma, and victimization have been shown to create a hostile and stressful social environment that can contribute to mental health problems (Clements-Nolle et al., 2006; Meyer, 2003). This finding is consistent with research in trans communities in the United States (Nemoto et al., 2006; Nuttbrock et al., 2010), and other populations that commonly experience social discrimination, including sexual (Diaz et al., 2001; Meyer, 2003) and racial minorities (Finch, Kolody, \& Vega, 2000).

Planning to medically transition but having not begun (versus having medically transitioned) was also a strong contributor to depressive symptomatology in both bivariate and multiple regression analyses. This finding is supported by research that suggests that among transsexual FTMs, operated patients suffer less depression than those undergoing a diagnostic phase (Mate-Kole, Freschi, \& Robin, 1988). Overall, trans people in the initial phases of transitioning may experience more distress than in later phases (Gomez-Gil, Vidal-Hagemeuer, \& Salamero, 2008; Mate-Kole et al., 1988). It is also possible, however, that depressed FTMs may be unable to medically transition as a result of being denied access to hormones and/or surgeries. This stems from the fact that psychotherapy with a mental health professional may be required as part of some medical transition processes; thus, trans patients may have to demonstrate improving or continuing stable mental health before hormones or surgeries are provided.

Finally, in bivariate analyses, those who reported being diagnosed with major mental health disorders were more likely to exhibit symptoms consistent with depression than FTMs who had never been diagnosed with these conditions. In multivariable analyses, having a major mental health condition approached significance as a risk factor for depression $(p=.0752)$. Given concerns with the potentially different effects of anxiety disorders on depressive mood (compared with schizophrenia, borderline personality disorder, and dissociative identity disorder), multivariable models were re-examined using a revised version of the mental health variable: diagnosed only with anxiety disorders; diagnosed with schizophrenia, borderline personality 
disorder, and/or dissociative identity disorder, along with (or without) anxiety disorders; and none (reference). The effects of the preceding mental health categories on depressive symptomatology were comparable in terms of the magnitude and direction of association.

In general, the comorbidity of depression with other mental health issues, particularly anxiety disorders, is common and may be explained by a causal relationship or a shared etiologic factor (Silberg, Rutter, \& Eaves, 2001). Longitudinal studies have indicated that anxiety disorders predate depression more often than the reverse (Silberg et al., 2001). Thus, being diagnosed with a major mental health condition may directly contribute to depressive mood. The present finding may also indicate, however, that transphobia is a shared risk factor for depressive symptomatology and other major mental health conditions, since subsequent analyses indicated that transphobia was significantly associated with the latter. This hypothesis is supported by research that demonstrates that discrimination and victimization are related to several measures of psychological distress, including anxiety and depression (Clements-Nolle et al., 2006). In addition, trans-specific difficulties in accessing mental health care exist. In the qualitative phase of Trans PULSE, participants reported a "double bind," in which providers were not able to see mental health issues as distinct from gender identity, and tended to either attribute mental health conditions to a client's gender identity or to attribute their gender identity to their mental health condition (Bauer et al., 2009).

\section{Strengths and Limitations}

The present study has strengths worth noting. First, it is the largest study of trans people in Canada and is the first to explore the effects of risk and protective factors unique to the trans community, as well as others strongly and consistently related to depression in broader populations. Second, our paper has identified and drawn attention to the burden of depressive symptoms in FTM Ontarians. Third, our sample was obtained using RDS, a probability-based method that allows for the calculation of asymptotically unbiased estimates of prevalence (Heckathorn, 2002). Several limitations exist, however. Our study is cross-sectional; thus, we cannot make causal assertions. Specifically, temporality is an issue given that depression can be a chronic condition that may precede (or cause) the factors of interest. Furthermore, RDS is only suitable for sampling populations with a contact pattern (Heckathorn, 2002), and it will not capture those who are entirely isolated from the trans community. It is possible that depression may be associated with such isolation among FTMs. Because statistics are weighted for network size, only a differential representation among those connected to no other trans people would be expected to affect results. While we were not able to examine data on those we could not reach, we did confirm that FTMs who had symptoms consistent with depression had smaller network sizes, with a median of 6 reported connections among depressed FTMs vs. 10 among non-depressed FTMs (Wilcoxon rank sum test, $p=.0135$ ).

Another limitation of our research is that we used a self-reported measure of current depressive symptomatology (CES-D) rather than a diagnosis of clinical depression. In fact, the CES-D assesses the occurrence of symptoms only during the past week and may be sensitive to temporal fluctuations in the depressive experience. Furthermore, the CES-D emphasizes depressed mood and does not have an item related to suicidal ideation. This was not a major issue in our paper, however, because we had included separate measures of suicidality in the Trans PULSE survey. 
While the CES-D showed high internal consistency in our data, a cut-point of $\geq 16$ may include mild depressive symptomatology and result in a high false positive rate, at least based on assessments of the CES-D in other populations (Zich, Attkisson, \& Greenfield, 1990). The CES-D has also been shown to suffer from differential item functioning related to gender differences in respondents' interpretation of, and propensity to endorse, certain items (Kalaian, Schulz, \& McCorkle, 1993; Bush \& Fedio, 1999). Given these limitations, our binary outcome variable may have contributed to the differential misclassification of depression in FTM Ontarians (i.e., scores may be biased upward). Therefore, future validation studies of the CES-D in trans communities are needed. Nonetheless, the CES-D has highly acceptable validity and reliability properties that hold across other population subgroups (Radloff, 1977), and it is commonly used both in general population and trans-related research.

Because there is no standard scale to measure exposure to transphobia, one was developed specifically for Trans PULSE. The scale was based on measures used in previous trans-related research (Sugano et al., 2006), and items were refined in collaboration with trans members of the research team to ensure face validity. Future research should focus efforts on developing a scale that may more accurately assess discrimination specific to being trans-identified. Finally, although point estimates derived from RDSAT are likely to be fairly reliable, their standard errors may not be (Wejnert, 2009). Regardless, procedures for variance estimation in RDS outperform the naïve approach in which the sampling design is ignored (Salganik, 2006).

In general, although our study has addressed a major gap in the literature, additional empirical evidence is needed to gain a firm understanding of the risk and protective factors for depression among FTMs.

\section{CONCLUSIONS}

Not surprisingly, our findings indicate that depressive symptomatology is widespread among FTM Ontarians and is a major health concern. This study is a first step in understanding the complex mental health issues of a highly marginalized community. As members of a gender minority, FTMs face a multitude of challenges that may affect health and well-being. In particular, experiences of transphobia increase depression risk in FTMs, while greater satisfaction in sexual relationships was protective. Being in a period of planning but not yet having begun a medical transition represented a point of vulnerability for mental health. These three factors remained independent predictors of depressive symptomatology, controlling for age, education,

abuse history, major mental health disorders, and other factors. Prospective studies are greatly needed to provide more evidence for causal associations and pathways.

\section{RÉSUMÉ}

Bien que la dépression soit sous-étudiée dans les communautés transgenres et transsexuelles, on rapporte des taux élevés de prévalence. Cet article présente des résultats inédits de recherche du projet Trans PULSE, une initiative à base communautaire en Ontario qui a recruté 433 participants et participantes en utilisant la méthode d'échantillonnage en fonction des répondants et répondantes. Le but de cette analyse était de déterminer la prévalence de la dépression ainsi que les facteurs de risque et de protection chez les personnes qui passent de femme à homme (FtM) en Ontario $(n=207)$. Nous estimons que $66,4 \%$ des FtM ont une symptomatologie compatible avec la dépression. Selon les analyses multivariées, la satisfaction sexuelle est un facteur puissant de protection contre la dépression. Inversement, les expériences de transphobie 
PREVALENCE OF AND RISK AND PROTECTIVE FACTORS FOR DEPRESSION IN FTM ONTARIANS

et le fait de planifier, mais de ne pas avoir commencé une transition médicale (hormones ou interventions chirurgicales) affectent défavorablement la santé mentale des FtM.

Mots clés : transgenre, femme vers homme, dépression, Ontario, facteurs de risque et facteurs protecteurs, échantillonnage en fonction des répondants et répondantes

\section{REFERENCES}

Aro, H. (1994). Risk and protective factors in depression: A developmental perspective. Acta Psychiatrica Scandinavica, 89(377, Suppl), 59-64.

Baldwin, D.S. (2001). Depression and sexual dysfunction. British Medical Bulletin, 57, 81-99.

Barret, J. (1998). Psychological and social function before and after phalloplasty. International Journal of Transgenderism, 2(1). Retrieved from http://www.iiav.nl/ezines/web/ijt/97-03/numbers/symposion/ijtc0301.htm

Bauer, G.R., Hammond, R., Travers, R., Kaay, M., Hohenadel, K.M., \& Boyce, M. (2009). "I don't think this is theoretical; this is our lives": How erasure impacts health care for transgender people. Journal of the Association of Nurses in AIDS Care, 20(5), 348-361.

Berglund, P.A. (2009). Getting the most out of the SAS survey procedures: Repeated replication methods, subpopulation analysis, and missing data options. In SAS v9.2. Cary, NC: SAS Institute Inc. Report No.: 246-2009.

Boyd, J.H., Weissman, M.M., Thompson, W.D., \& Myers, J.K. (1982). Screening for depression in a community sample: Understanding the discrepancies between depression symptom and diagnostic scale. Archives of General Psychiatry, 39, 1195-1200.

Brown, G.K. (1990). A causal analysis of chronic pain and depression. Journal of Abnormal Psychology, 99(2), 127-137.

Bush, B.A., \& Fedio, P. (1999). Gender differences and the CES-D in the first year post stroke. Archives of Clinical Neuropsychology, 14(1), 123.

Clements-Nolle, K., Marx, R., Guzman, R., \& Katz, M. (2001). HIV prevalence, risk behaviors, health care use, and mental health status of transgender persons: Implications for public health intervention. American Journal of Public Health, 91, 915-921.

Clements-Nolle, K., Marx, R., \& Katz, M. (2006). Attempted suicide among transgender persons: The influence of gender-based discrimination and victimization. Journal of Homosexuality, 51(3), 53-68.

Coelho, R., Silva, C., Maia, A., Prata, J., \& Barros, H. (1999). Bone mineral density and depression: A community study in women. Journal of Psychosomatic Research, 46(1), 29-35.

Couch, M., Pitts, M., Mulcare, H., Croy, S., Mitchell, S., \& Patel, S. (2007). Tranznation: A report on the health and wellbeing of transgendered people in Australia and New Zealand (Series no. 65). Melbourne, Australia: Australian Research Centre in Sex, Health \& Society. Retrieved on August 8, 2011, from http://www.glhv.org. au/files/Tranznation_Report.pdf.

De Cuypere, G., Elaut, E., Heylens, G., Van Maele, G., Selvaggi, G., T’Sjoen, G., . . Monstrey, S. (2006). Long-term follow-up: Psychosocial outcome of Belgian transsexuals after sex reassignment surgery. Sexologies, 15, 126-133.

Dean, L., Meyer, I.H., Robinson, K., Sell, R.L., Sember, R., Silenzio, V.M.B., . . Xavier, J. (2000). Lesbian, gay, bisexual, and transgender health: Findings and concerns. Journal of the Gay and Lesbian Medical Association, 4(3), 102-151.

Diaz, R.M., Ayala, G., Bein, E., Henne, J., \& Marin, B.V. (2001). The impact of homophobia, poverty, and racism on the mental health of gay and bisexual Latino men: Findings from three US cities. American Journal of Public Health, 91(6), 927-932.

Fann, J.R., Thomas-Rich, A.M., Katon, W.J., Cowley, D., Pepping, M., McGregor, B.A., \& Gralow, J. (2008). Major depression after breast cancer: A review of epidemiology and treatment. General Hospital Psychiatry, 30, 112-126.

Finch, B.K., Kolody, B., \& Vega, W.A. (2000). Perceived discrimination and depression among Mexican-origin adults in California. Journal of Health and Social Behavior, 41(3), 295-313.

Gapka, S., \& Raj, R. (2003). Trans health project: A position paper and resolution adopted by the Ontario Public Health Association (OPHA) (No. 2003-06). Toronto, ON: Ontario Public Health Association. Retrieved from http://www. opha.on.ca/our_voice/ppres/papers/2003-06_pp.pdf 
Gomez-Gil, E., Vidal-Hagemeuer, A., \& Salamero, M. (2008). MMPI-2 characteristics of transsexuals requesting sex reassignment: Comparison of patients in prehormonal and presurgical phases. Journal of Personality Assessment, 90(4), 368-374.

Heckathorn, D.D. (1997). Respondent-driven sampling: A new approach to the study of hidden populations. Social Problems, 44(2), 174-199.

Heckathorn, D.D. (2002). Respondent-driven sampling II: Deriving valid population estimates from chain-referral samples of hidden populations. Social Problems, 49(1), 11-34.

Hepp, U., Kraemer, B., Schnyder, U., Miller, N., \& Delsignore, A. (2005). Psychiatric comorbidity in gender identity disorder. Journal of Psychosomatic Research, 58, 259-261.

Kalaian, H.A., Schulz, R. \& McCorkle, R. (1993). Gender bias in the measurement properties of the Center for Epidemiological Studies Depression Scale (CES-D). Psychiatry Research, 49(3), 239-250.

Lesage, A., Vasiliadis, H.M., Gagné, M.-A., Dudgeon, S., Kasman, N., \& Hay, C. (2006). Prevalence of mental illness and related service utilization in Canada: An analysis of the Canadian Community Health Survey. Mississauga, ON: Canadian Collaborative Mental Health Initiative. Retrieved from http:/www.ccmhi.ca/en/products/ documents/09 Prevalence EN.pdf

Lombardi, E.L., Wilchins, R.A., Priesing, D., \& Malouf, D. (2001). Gender violence: Transgender experiences with violence and discrimination. Journal of Homosexuality, 42(1), 89-101.

Maguen, S., Shipherd, J.C., \& Harris, H.N. (2005). Providing culturally sensitive care for transgender patients. Cognitive and Behavioral Practice, 12(4), 479-490.

Mate-Kole, C., Freschi, M., \& Robin, A. (1988). Aspects of psychiatric symptoms at different stages in the treatment of transsexualism. British Journal of Psychiatry, 152, 550-553.

Meyer, I.H. (2003). Prejudice, social stress, and mental health in lesbian, gay, and bisexual populations: Conceptual issues and research evidence. Psychological Bulletin, 129(5), 674-697.

Nemoto, T., Operario, D., Sevelius, J., Keatley, J., Han, L., \& Nguyen, H. (2006). Transphobia among transgenders of color. Retrieved from http://www.caps.ucsf.edu/uploads/pubs/presentations/pdf/APHA_Nemoto.pdf

Newfield, E., Hart, S., Dibble, S., \& Kohler, L. (2006). Female-to-male transgender quality of life. Quality of Life Research, 15(9), 1447-1457.

Nuttbrock, L., Hwahng, S., Bockting, W., Rosenblum, A., Mason, M., Macri, M., \& Becker, J. (2010). Psychiatric impact of gender-related abuse across the life course of male-to-female transgender persons. Journal of Sex Research, 47(1), 12-23.

Operario, D., \& Nemoto, T. (2005). Sexual risk behavior and substance use among a sample of Asian Pacific Islander transgendered women. AIDS Education and Prevention, 17(5), 430-443.

Pigott, T.D. (2001). A review of methods for missing data. Educational Research and Evaluation, 7(4), $353-383$.

Rabkin, J.G. (2008). HIV and depression: 2008 review and update. Current HIV/AIDS Report, 5, 163-171.

Radloff, L.S. (1977). The CES-D scale: A self-report depression scale for research in the general population. Applied Psychological Measurement, 1, 385-401.

RDSAT 5.6 User Manual. (2006). Retrieved from http://www.respondentdrivensampling.org/

Rosser, B.R.S., Oakes, J.M., Bockting, W.O., \& Miner, M. (2007). Capturing the social demographics of hidden sexual minorities: An internet study of the transgender population in the United States. Sexuality Research \& Social Policy, 4(2), 50-64.

Salganik, M.J. (2006). Variance estimation, design effects, and sample-size calculations for respondent-driven sampling. Journal of Urban Health, 83(7), i98-i112.

SAS Institute, I. (2010). SAS software, 9.2. Cary, NC.

Sherbourne, C.D., \& Stewart, A.L. (1991). The MOS social support survey. Social Science \& Medicine, $32(6), 705-714$.

Silberg, J.L., Rutter, M., \& Eaves, L. (2001). Genetic and environmental influences on the temporal association between earlier anxiety and later depression in girls. Biological Psychiatry, 49(12), 1040-1049.

Snell, W.E. (1998). The multidimensional sexual self-concept questionnaire. In C.M. Davis, W.L. Yarber, R. Bauseman, G. Schreer, \& S.L. Davis (Eds.), Handbook of sexuality-related measures (pp. 521-524). Thousand Oaks, CA: Sage.

Sugano, E., Nemoto, T., \& Operario, D. (2006). The impact of exposure to transphobia on HIV risk behavior in a sample of transgendered women of color in San Francisco. AIDS and Behavior, 10(2), 217-224. 
PREVALENCE OF AND RISK AND PROTECTIVE FACTORS FOR DEPRESSION IN FTM ONTARIANS

Volz, E., Wejnert, C., Degani, I., \& Heckathorn, D.D. (2007). Respondent-driven sampling analysis tool (RDSAT) Version 6.0. Ithaca, NY: Cornell University.

Wejnert, C. (2009). An empirical test of respondent-driven sampling: Point estimates, variance, degree measures, and out-of-equilibrium data. Sociological Methodology, 39(1), 73-116.

Zich, J.M., Attkisson, C.C., \& Greenfield, T.K. (1990). Screening for depression in primary care clinics: The CES-D and the BDI. International Journal of Psychiatry in Medicine, 20(3), 259-277. 